\title{
Screening of bacteria for antagonistic activity against phytopathogens of avocados.
}

\author{
Christopher A. Dunlap ${ }^{1}$ * Shiloh Lueschow ${ }^{1}$, Daniel Carrillo ${ }^{2}$ and Alejandro P. Rooney ${ }^{1}$ \\ ${ }^{1}$ Crop Bioprotection Research Unit, National Center for Agricultural Utilization Research, \\ Agricultural Research Service, United States Department of Agriculture, Peoria, IL, USA \\ ${ }^{2}$ University of Florida, Tropical Research and Education Center, Homestead, FL, USA
}

*Address correspondence to Christopher A. Dunlap, christopher.dunlap@ars.usda.gov 


\begin{abstract}
Avocado trees in Florida and California are under attack, respectively, from laurel wilt and Fusarium dieback, two diseases caused by fungi that live in symbiosis with amrbosia beetle species. As a first step to identify possible bacteria that can be utilized as biocontrol agents against these important diseases of avocados, we isolated microorganisms from avocado trees in Florida to determine their potential for use as biocontrol antagonists against the pathogens responsible for laurel wilt and Fusarium dieback. In addition, we assessed the potential of other strains not isolated from avocado to determine their effectiveness as biocontrol antagonists. A total of 50 strains were identified as strong antagonists against the laurel wilt pathogen, Raffaelea lauricola. Fifteen of the most active strains were, in turn, evaluated for antagonism against Fusarium euwallaceae, the causal agent of Fusarium dieback on avocados. Four strains representing three Paenibacillus species and one Bacillus species were found to be active against both $R$. lauricola and F. euwallaceae. This study is the first to report antifungal or antagonist activity of bacterial strains effective against avocado pathogens vectored by ambrosia beetles, and it is also the first to report the effectiveness of Paenibacillus thiaminolyticus or Paenibacillus apiarius against a phytopathogen.
\end{abstract}




\section{Introduction}

Persea Americana, or the avocado tree, has been an important United States agricultural crop after first being planted in 1833 in Florida (AgMRC report 2016). In 2011, avocados accounted for an estimated \$492.1 million in revenue in the United States. Currently, California is responsible for the majority of avocado production (85-90\%) in the United States and whereas Florida is a distant second (10-15\%). Nonetheless, avocados have an estimated economic impact of \$54 million per year in Florida (Evans et al. 2010), which makes it Florida's second largest fruit commodity behind citrus fruits and underscores its importance to that state's economy. Thus, it is not surprising that a considerable level of concern has been raised over the threat posed to the Florida avocado industry by the redbay ambrosia beetle (Xyleborus glabratus) and the fungal symbiont held in its mycangia, Raffaelea lauricola (Harrington et al., 2008; Evans et al., 2010).The redbay ambrosia beetle (RAB), a native to Asia, was first discovered in the United States in Savannah, Georgia in 2002. The beetle harbors a fungus in its mouthparts that is the causal agent of laurel wilt (Fraedrich et al. 2008), a disease of trees in the family Lauraceae which includes redbay and swampbay trees as well as avocado. Upon boring into a host tree, the fungi held in the mycangia in the mouthparts of female RABs begin to grow and eventually serve as a food source for developing RAB larvae. Unfortunately, this fungus is also the causal agent of laurel wilt (Fraedrich et al. 2008), and in 2008 it was formally described as Raffaelea lauricola (Fraedrich et al., 2008; Harrington et al., 2008). Since its arrival in the United States, the RAB has spread through much of the southeastern part of the country, from North Carolina on the northeastern edge of its range to Mississippi on the western edge. From 2005 through 2007, the RAB spread through much of Florida and in 2007 the first avocado tree death was seen near Jacksonville (Mayfield Iii et al., 2008). It is believed that like its host, $R$. lauricola is also an Asian native. Nevertheless, Carrillo et al. demonstrated that other ambrosia 
beetles (including native North American species) can also carry and transmit $R$. lauricola to healthy avocados and other Persea species (Carrillo et al. 2014).

Within the last few years, another ambrosia beetle-fungal symbiont complex that causes disease on avocado was discovered in Israel (Freeman et al. 2013). The disease caused by this complex is known as Fusarium dieback and is caused by a species of Fusarium ((Eskalen et al., 2012) carried by two members of the Euwallacea fornicatus species complex (Kasson et al., 2013; O'Donnell et al., 2015). The disease first appeared in Israel (Freeman et al. 2013) but has showed up in California not long afterwards (Eskalen et al., 2012). The E. fornicatus species complex includes both the polyphagous shot hole borer and the tea shot hole borer (O'Donnell et al. 2015). The polyphagous shot hole borer carries the symbiont responsible for Fusarium dieback, which was later identified as Fusarium euwallaceae (Freeman et al., 2013). This fungus has the capacity to damage the xylem of avocado trees and cause branch dieback.

The severe consequences of these pathogens have led to studies involving the prevention of infection or elimination of the pathogens after infection. Based on a study (Cassar and Blackwell, 1996) and the species description by Harrington et al. 2008, R. lauricola is tolerant to the antifungal cycloheximide even at high concentrations. In 2011, Ploetz et al. completed a study looking at the potential to use a variety of fungicides to manage laurel wilt within avocado trees. They saw some success on both plates with fungicides and on potted plants but doubted the efficacy and cost effectiveness of using these fungicides on a large or commercial tree scale (Ploetz et al., 2011). Furthermore, a study by Carrillo et al. (2015) tested the effectiveness of entomopathogenic fungi as a biocontrol for the RAB. Death of RAB adults was observed between three to five days post-inoculation depending on which the fungus species was being tested, but this interim period between fungal exposure and death still allowed the beetles time 
to produce galleries and potentially inoculate the tree with $R$. lauricola (Carrillo et al., 2015). In comparison to the variety of strategies and studies done to combat laurel wilt, there has been little to no published research done thus far looking at ways to control Fusarium dieback (Umeda et al., 2016). At this point in time the use of insecticides, sanitization of trees, and trapping of insects are some of the limited ways farmers have been trying to combat the spread of Fusarium dieback (Umeda et al., 2016). Clearly, methods of control for both laurel wilt and Fusarium dieback are urgently needed in order to check the spread of this disease on avocado and other trees. The goals of this study were: i.) to culture, isolate, and identify natural microbial communities found on the bark of avocado trees from Florida; ii.) to screen those isolates for in vitro antagonism against $R$. lauricola and $F$. euwallaceae; and iii.) to screen an in-house collection of bacteria in vitro antagonism against $R$. lauricola and F. euwallaceae.

\section{Materials and Methods}

\section{Isolation and identification of avocado bark associated microbes}

Bolts of wood from the secondary branches of a healthy and nonsprayed Persea americana 'Lula' tree were collected from an avocado orchard at the Tropical Research and Education Center (TREC) in Homestead, Florida. The bark was removed from the wood and pieces were put in $50 \mathrm{~mL}$ conical vials with $40 \mathrm{~mL}$ sterile deionized water and put on a rocker for 30 minutes with vortexing every 10 minutes. Dilutions of $1: 10$ and 1:100 were then streaked onto five plates for each dilution of Yeast Mold (YM) agar with $50 \mathrm{mg} / \mathrm{L}$ chloramphenicol. Plates were incubated at $30^{\circ} \mathrm{C}$ and isolates were taken from the plates as they grew. 
DNA was extracted from fungal mycelia or bacterial cells using a CTAB method (Zhang et al., 2010), followed by PCR and sequencing to determine the identity of the isolate. The ITS region was used for fungal identification and the $16 \mathrm{~S}$ region was used for bacterial identification. ITS PCR was done with primers V9D (5' - TTAAGTCCCTGCCCTTTGTA - 3') and LS266 (5' - GCATTCCCAAACAACTCGACTC -3') as well as D1D2 primers NL-1 (5' GCATATCAATAAGCGGAGGAAAAG - 3') and NL-4 (5' - GGTCCGTGTTTCAAGACGG $\left.-3^{\prime}\right)$ under the following condition: initial denaturation $95^{\circ} \mathrm{C}$ for ten minutes; followed by 35 cycles of $95^{\circ} \mathrm{C}$ for 30 seconds, $55^{\circ} \mathrm{C}$ for 30 seconds, and $72^{\circ} \mathrm{C}$ for one minute; and a final extension at $72^{\circ} \mathrm{C}$ for seven minutes. $16 \mathrm{~S}$ PCR was done with primers $27 \mathrm{~F}\left(5^{\prime}-\right.$ AGAGTTTGATCCTGGCTCAG - 3') and 1492R (5' - GGTTACCTTGTTACGACTT - 3') with the same PCR parameters used for the ITS region. Isolate sequences were then identified using Ez-taxon and the ITS2 database depending on whether they were bacterial or fungal (Kim et al., 2012; Koetschan et al., 2012).

\section{Microorganisms}

A Raffaelea lauricola culture was obtained from the Florida Extension Plant Diagnostic Clinic located at TREC. The identity of this culture was previously confirmed as $R$. lauricola with two diagnostic microsatellite markers as described by Dreaden et al. 2014. Spores of $R$. lauricola were produced on Potato Dextrose Agar (PDA) or Malt Extract Agar (MEA) and grown at 30 ${ }^{\circ} \mathrm{C}$. Fusarium euwallaceae strains AF2 and AF12 were provided by Kerry O'Donnell at the U.S. Department of Agriculture, National Center for Agricultural Utilization Research. Spores of $F$. euwallaceae were produced on Tryptic Soy Agar (TSA) or PDA and grown at $30^{\circ} \mathrm{C}$. A 
collection of bacteria from different genera (Table S1) were obtained from the ARS Culture Collection (http://nrrl.ncaur.usda.gov/).

\section{In vitro antagonism assay against $R$. lauricola}

Isolates were streaked in a small circle in the center of 1/10 Reasoner's $2 \mathrm{~A}, \mathrm{R} 2 \mathrm{~A}$, and grown for 48 to 72 hours at $30^{\circ} \mathrm{C}$ until colonies were clearly present on the plate. A spore solution of $R$. lauricola made with $0.04 \%$ tween was then produced and sprayed using a Sprātool@ power-pack over the plate. After 72 hours, the plates were checked for the presence or absence of a zone of inhibition around the isolate in the middle of the plate. Depending on the size of the zone of inhibition or the growth pattern of the isolate, they were rated on a scale of 1 to 3 for their effectiveness as a biocontrol against the pathogen, with 1 being no antagonism, 2 weak antagonism and 3 strong antagonism.

\section{In vitro antagonism assay against $F$. euwallaceae}

Isolates that demonstrated in vitro antagonisms against R. lauricola were further tested for activity against $F$. euwallaceae. Isolates were streaked on two 1/10 R2A plates in small circles and allowed 48 to 72 hours at $30^{\circ} \mathrm{C}$ until growth was clear on the plate. One plate was then sprayed with Fusarium strain AF2, while the other was sprayed with Fusarium strain AF12.

Seventy-two hours were then allowed to pass and the isolates were rated for their effectiveness against the Fusarium strains on a 1 to 3 scale as described above. A strain was considered positive if it had activity against at least one of the Fusarium strains.

\section{Phylogenetic trees}


The phylogenetic trees were constructed with $16 \mathrm{~S}$ rRNA sequence data generated as described above. Sequences were aligned using CLC Bio Genomics workbench 9.0 (Qiagen Inc); the resulting alignment was visually checked for errors and manually adjusted. Phylogenetic analysis was conducted with MEGA 6 (Tamura et al., 2013) using the neighbor-joining (NJ) method (Saitou and Nei, 1987). For NJ analysis, the Kimura two parameter model with nonuniformity of substitution rates modeled by a gamma distribution (shape parameter $=0.3$ ) was used, as this model was found to be the best-fit using the likelihood-based model selection algorithm implemented in MEGA 6. The partial deletion (90\%) option was used and the level of bootstrap support was calculated from 1,000 replicates.

\section{Results and Discussion}

\section{Avocado isolates}

After having isolated several hundred colonies from avocado bark, a total of 61 were selected for further antagonist testing on the basis of unique colony morphology and appearance. The isolates were typed to species level using standard molecular identification methods (e.g. (Rooney et al., 2009; Kasson et al., 2013) and were found to encompass 19 different genera, with eleven being bacterial and eight being fungal (Figure 1). The bacterial genus with the highest represented abundance within the avocado isolates was Bacillus with $44 \%$ of the bacterial isolates falling within this genus (Figure 1). Bacillus species have been commonly found in agricultural soils and have been found to induce plant growth promotion; increase yield, growth, and survival of various plant species; and produce antifungal metabolites (Lyngwi and Joshi, 2014). Additionally, other common soil bacteria were found in the bark of the avocado tree, which may produce antimicrobial secondary metabolites, such as Enterobacter, 
Arthrobacter, Pseudomonas and Streptomyces (Elango et al., 2015; Halfeld-Vieira et al., 2015; Li et al., 2015; Arzanlou et al., 2016)

Similar to the bacterial microbiome, the fungal mycobiome that was characterized also had certain species that displayed higher relative abundance than the other fungal genera that were characterized (Figure 1). In this case, Fusarium and Penicillium were the most abundant fungal genera within the avocado tree mycobiome and accounted for $64 \%$ of all fungal isolates. The most commonly isolated fungus from the avocado bark was Fusarium. Fusarium is considered to be a phytopathogenic genus in general, due to many species being capable of causing some kind disease in plants (Ward et al., 2002; Aoki et al., 2014). In the avocado tree, F. euwallaceae could be causing opportunistic infections when the tree becomes compromised or stressed either environmentally or due to a true pathogen infection.

\section{In vitro antagonism of $R$. lauricola}

A preliminary screening of the bacterial strains isolated from avocado bark provided no strains with in vitro antagonism activity against $R$. lauricola. Our screening was expanded to include an in-house collection of 181 isolates of species from the bacterial families Bacillaceae (Bacillus, Lysinibacillus, Solibacillus, Rummelibacillus, Virgibacillus and Viridibacillus) and Paenibacillaceae (Paenibacillus). These species were selected on the basis of strains of Bacillaceae and Paenibacillaceae are commonly isolated as plant-associated biocontrol agents and plant growth promoters. The in-house collection provided 70 different isolates with in vitro antagonism activity against $R$. lauricola, 50 of the isolates were classified as strong antagonists and the other 20 were classified as weak antagonists. The antagonist activity came from a broad 
diversity of the species assayed. (Figure 2 and 3). The activity also tended to follow phylogenetic relationships, with species of Bacillaceae more likely to be active than Paenibacillaceae. For example in the Paenibacillus genus (Fig 2), isolates Paenibacillus thiaminolyticus, Paenibacillus chitinolyticus and Paenibacillus peoriae were commonly identified as antagonists, while isolates of Paenibacillus larvae and Paenibacillus aliginolyticus were not active. In the Bacillaceace family (Fig 3), many of the Lysinibacillus and Bacillus species were antagonists, while isolates from Solibacillus, Viridibacillus and Rummeliibacillus gave mixed results.

\section{In vitro antagonism of $F$. euwallaceae}

A phylogenetically diverse subset of 15 strains with strong antagonism against $R$. lauricola was chosen to be evaluated against $F$. euwallaceae. Only 4 of the isolates showed any ability to antagonize the pathogen (Table 1). The strains were represented by three Paenibacillus species and one Bacillus species.

Stain NRRL B-14606 exhibited antagonism activity against both $R$. lauricola and $F$. euwallaceae. The strain was accessioned into NRRL as Paenibacillus thiaminolyticus and we confirmed this identification. This strain was originally isolated from human feces, whereas other P. thiaminolyticus have been isolated from honey larvae (Nakamura, 1990). We can find no reports of $P$. thiaminolyticus being isolated as a biocontrol antagonists or possessing antifungal activity. However, a $P$. thiaminolyticus strain has recently been reported to produce the antibacterial compound paenibacterin (Huang and Yousef, 2014).

Strain NRRL B-4303 also exhibited antagonism activity against both $R$. lauricola and $F$. euwallaceae. The strain was accessioned into NRRL as Paenibacillus apiarius and we 
confirmed this identification. $P$. apiarius is closely related to $P$. thiaminolyticus (Iiyama et al., 2014). P. apiarius strains have been isolated from honey larvae, although they are not entomopathogenic (Nakamura, 1996). We found no reports of $P$. apiarius being isolated as a biocontrol antagonist or possessing antifungal activity.

Strain NRRL B-14372 exhibited antagonism activity against both $R$. lauricola and $F$. euwallaceae. The strain was accessioned into NRRL as Paenibacillus azotofixans and we subsequently identified it as a Paenibacillus peoriae based on 16S rRNA sequencing. Unlike the other two Paenibacillus species, P. peoriae has been isolated before as a fungal antagonist (Von Der Weid et al., 2003; Lorentz et al., 2006; Jung et al., 2012).

Strain NRRL B-2522 showed some of the highest antagonism activity against $R$. lauricola and F. euwallaceae. . Although the strain was accessioned into NRRL as Paenibacillus lentimorbus, we subsequently identified it as a Bacillus velezensis. Our laboratory recently reported B. velezensis was the basonym of a group of important biocontrol strains, with common biocontrol species Bacillus methylotrophicus and Bacillus amyloliquefaciens subsp. plantarum being later synonyms (Dunlap et al., 2016). Strains from this species are the second most important group of commercialized prokaryotic biocontrol strains after Bacillus thuringiensis (Cawoy et al., 2011). Their antifungal activity is primarily due to the lipopeptides iturin and fengycin, which are conserved among all members of the species (Dunlap et al., 2013; Dunlap et al., 2016) and is consistent with the current study showing that B. velezensis had strong antagonism against both $R$. lauricola and $F$. euwallaceae.

Paenibacillus species are common among soils and rhizosphere of agricultural land (McSpadden Gardener, 2004). Also, they are commonly used as growth promoters and 
antimicrobial producers (McSpadden Gardener, 2004). Additionally, some Paenibacillus species have the ability to produce enzymes which degrade cells walls of phytopathogens and can stimulate the plant immune system (Lyngwi and Joshi, 2014). Members of this species show strong potential to be used as antagonist agents for biological control of plant pathogens based on the fact that they are common agricultural soil microbes with the capacity to destroy fungi through a varied array of metabolites that these species produce that exert antifungal effects (Lee et al., 2015; Vater et al., 2015; Bach et al., 2016; Xu and Kim, 2016).

\section{Conclusions}

In recent years, avocados in the United States have been threatened by fungal species harbored in the mycangia of ambrosia beetles. This study is the first to identify and characterize bacteria capable of antagonizing these important pathogens. This research also identified two species, $P$. thiaminolyticus and $P$. apiaries, that have not previously been reported to possess antifungal activity or to have been isolated as biocontrol antagonists of phytopathogens. Future research should be directed at determining how to effectively put these biocontrol agents in contact with $R$. lauricola and F. euwallaceae in an infected avocado tree; determining whether they can be used in unison to offer a synergistic effect; and conducting subsequent field trials once an effective in planta antagonist (or antagonist combination) and delivery methodology is established. Furthermore, there have been a limited number of studies looking at the microbial community of avocado trees by culture or sequence based methods. This study has determined a segment of the microbial community present in the bark of Florida avocado trees using culture based techniques, which provides a basis for the analysis of other potential biocontrol antagonists 
found on avocado trees. This study also offers a stepping stone for future microbiome studies that aim to get a more complete picture of the entire community and the role of individual microbial species in the beetle-fungus-tree disease complex.

\section{Acknowledgements}

The authors would like to thank Heather Walker of the National Center for Agricultural Utilization Research, Peoria, IL, USA, for expert technical assistance. Any opinions, findings, conclusions, or recommendations expressed in this publication are those of the author(s) and do not necessarily reflect the view of the U.S. Department of Agriculture. The mention of firm names or trade products does not imply that they are endorsed or recommended by the USDA over other firms or similar products not mentioned. USDA is an equal opportunity provider and employer. 


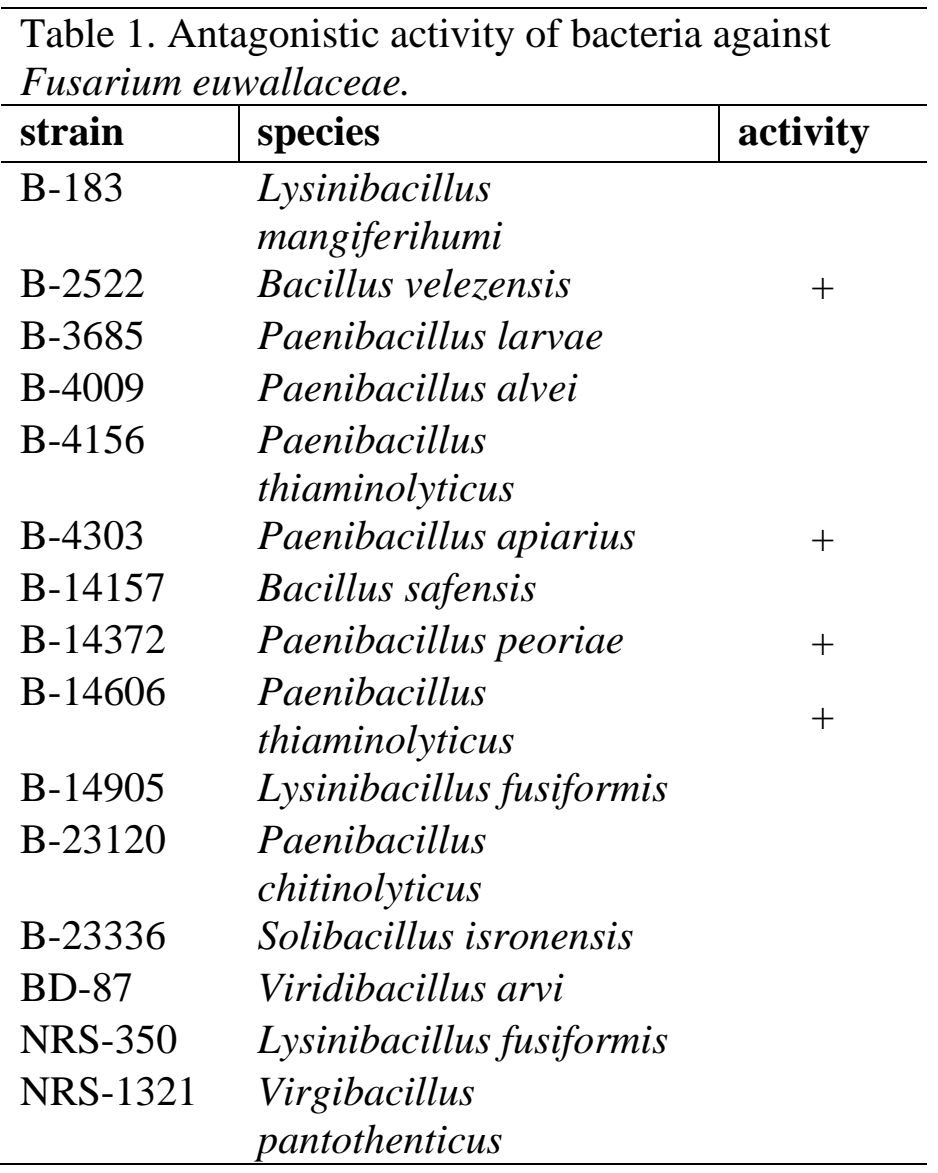




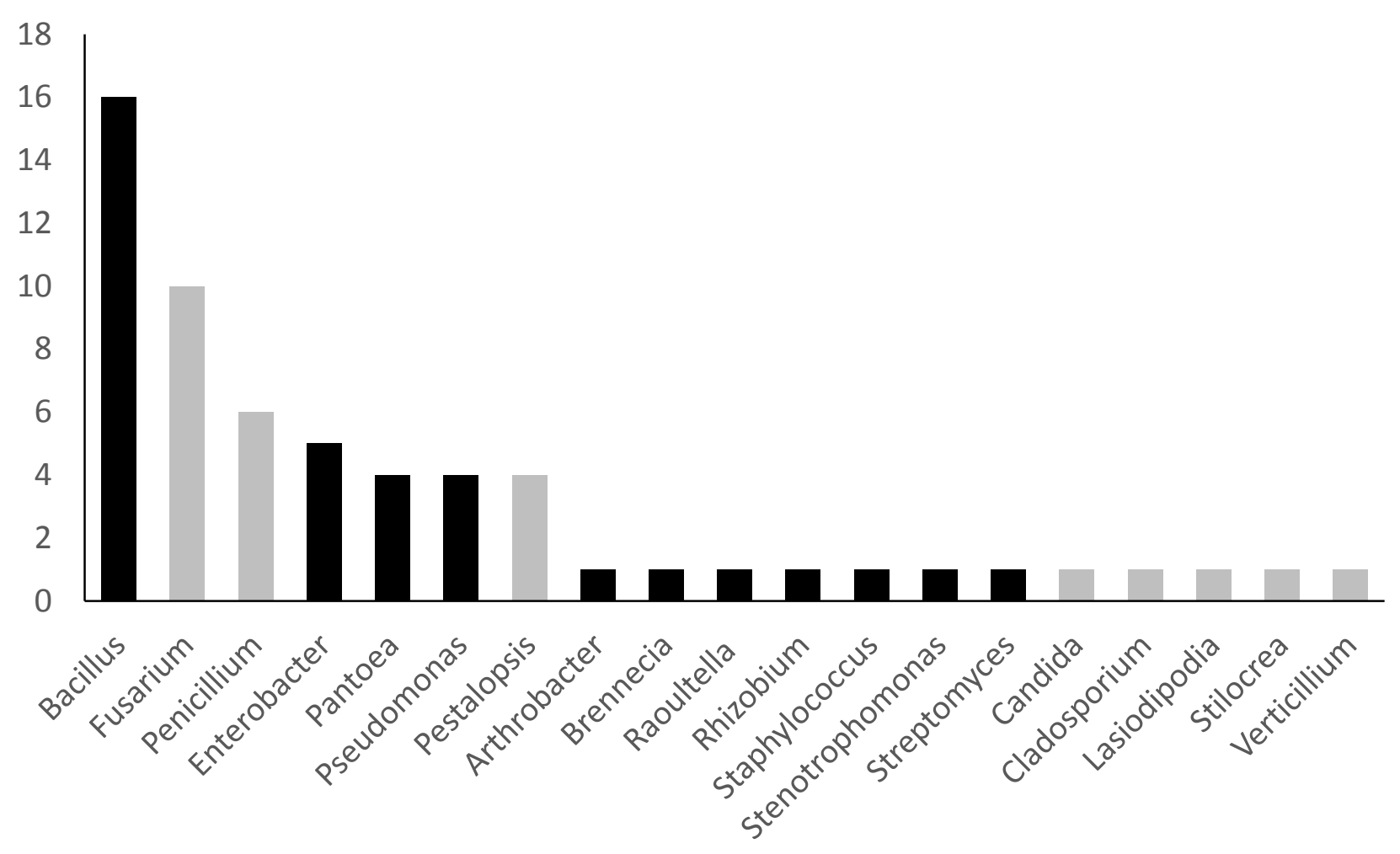

Figure 1. Relative abundance of isolates from avocado bark in bacterial (black bars) and fungal (gray bars) genera. 


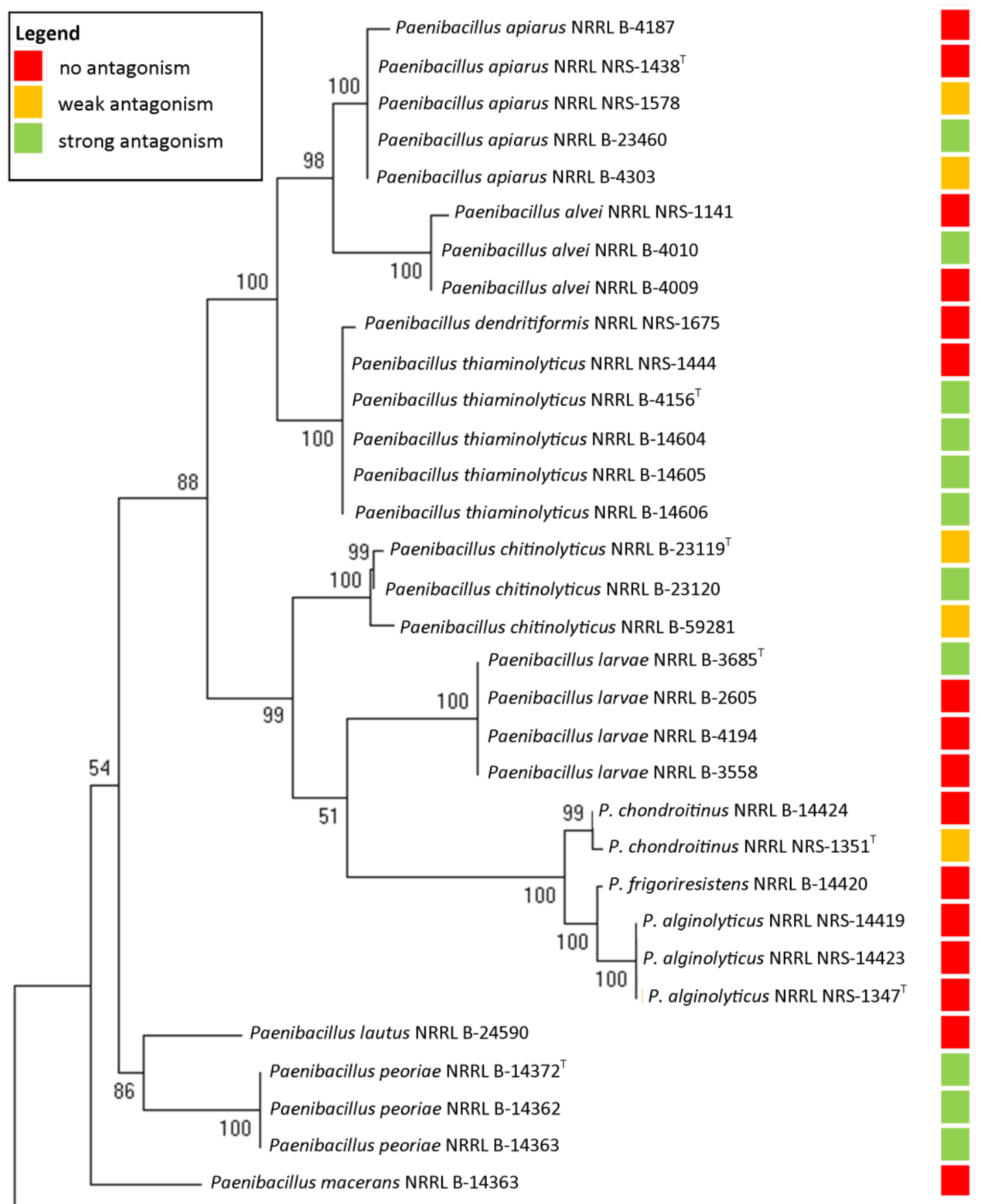

Lysinibacillus magniferihumi NRRL B-23268

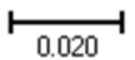

Figure 2. Phylogeny and antagonism activity of selected Paenibacillus strains against against $R$. lauricola. 


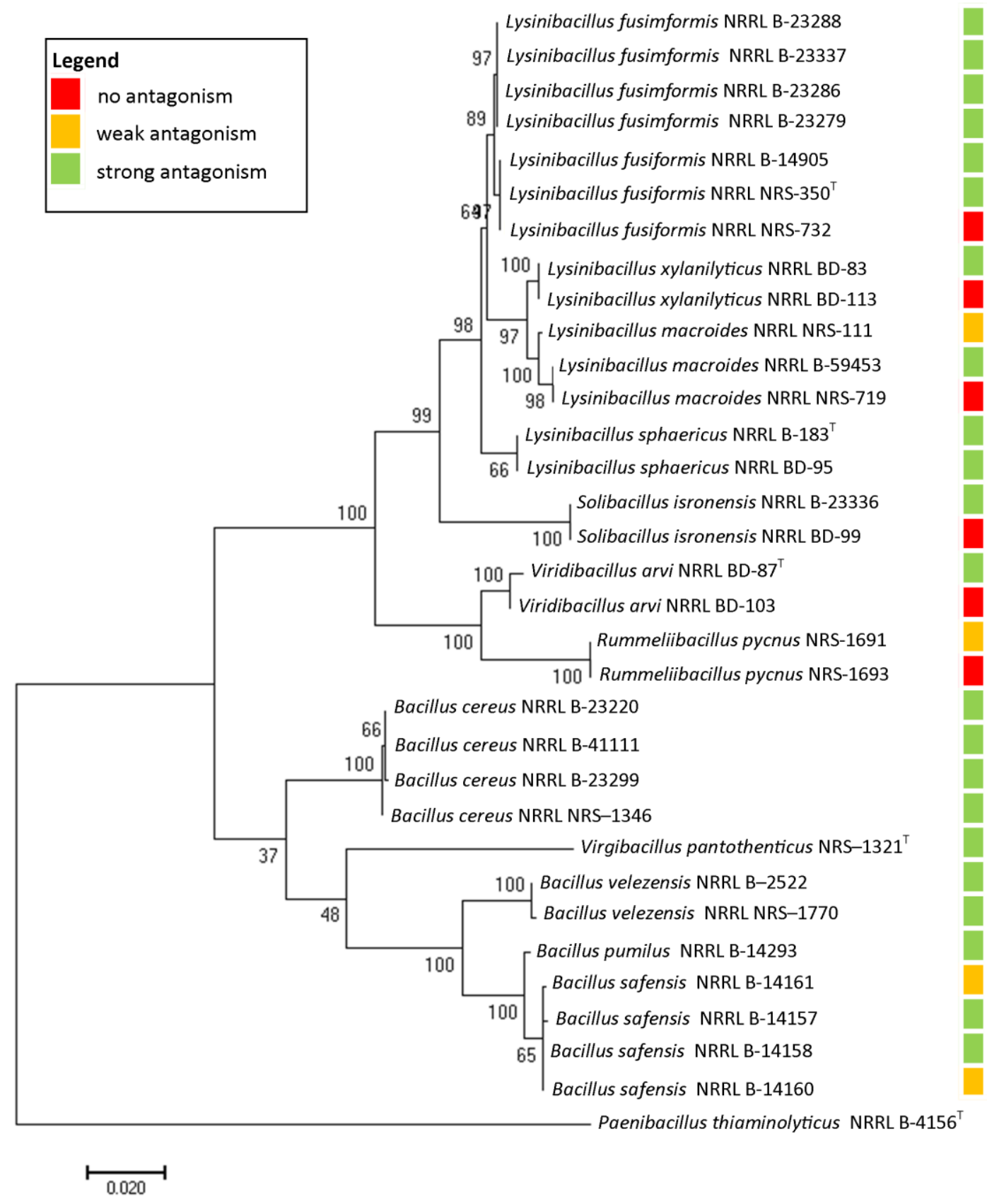

Figure 3. Phylogeny and antagonism activity of selected Bacilliceae species against $R$. lauricola. 


\section{References}

AgMRC report, 2016. Avocado report for the U.S. http://www.agmrc.org/commoditiesproducts/fruits/avocados/ (accessed 16.08.17).

Aoki, T., O'Donnell, K. and Geiser, D.M.: 2014. Systematics of key phytopathogenic Fusarium species: Current status and future challenges. Journal of General Plant Pathology 80, 189-201.

Arzanlou, M., Mousavi, S., Bakhshi, M., Khakvar, R. and Bandehagh, A.: 2016. Inhibitory effects of antagonistic bacteria inhabiting the rhizosphere of the sugarbeet plants, on Cercospora beticola Sacc., the causal agent of Cercospora leaf spot disease on sugarbeet. Journal of Plant Protection Research 56, 6-14.

Bach, E., Seger, G.D.D.S., Fernandes, G.D.C., Lisboa, B.B. and Passaglia, L.M.P.: 2016. Evaluation of biological control and rhizosphere competence of plant growth promoting bacteria. Applied Soil Ecology 99, 141-149.

Carrillo, D., Dunlap, C.A., Avery, P.B., Navarrete, J., Duncan, R.E., Jackson, M.A., Behle, R.W., Cave, R.D., Crane, J., Rooney, A.P. and Peña, J.E.: 2015. Entomopathogenic fungi as biological control agents for the vector of the laurel wilt disease, the redbay ambrosia beetle, Xyleborus glabratus (Coleoptera: Curculionidae). Biological Control 81, 44-50.

Cassar, S. and Blackwell, M.: 1996. Convergent origins of ambrosia fungi. Mycologia 88, 596601.

Cawoy, H., Bettiol, W., Fickers, P. and Ongena, M.: 2011 Bacillus-Based Biological Control of Plant Diseases. In: Stoytcheva, M. (Ed.), Pesticides in the Modern World - Pesticides Use and Management. InTech, Shanghai, China.

Dunlap, C.A., Bowman, M.J. and Schisler, D.A.: 2013. Genomic analysis and secondary metabolite production in Bacillus amyloliquefaciens AS 43.3: a biocontrol antagonist of Fusarium Head Blight. Biological Control 64, 166-175.

Dunlap, C.A., Kim, S.-J., Kwon, S.-W. and Rooney, A.P.: 2016. Bacillus velezensis is not a later heterotypic synonym of Bacillus amyloliquefaciens; Bacillus methylotrophicus, Bacillus amyloliquefaciens subsp plantarum and 'Bacillus oryzicola' are later heterotypic synonyms of Bacillus velezensis based on phylogenomics. International Journal of Systematic and Evolutionary Microbiology 1212-1217.

Elango, V., Manjukarunambika, K., Ponmurugan, P. and Marimuthu, S.: 2015. Evaluation of Streptomyces spp. for effective management of Poria hypolateritia causing red root-rot disease in tea plants. Biological Control 89, 75-83.

Eskalen, A., Gonzalez, A., Wang, D.H., Twizeyimana, M., Mayorquin, S.J. and Lynch, S.C.: 2012. First report of a Fusarium sp. and its vector tea shot hole borer (Euwallacea fornicatus) causing Fusarium dieback on avocado in California. Plant Disease 96, 1070. 
Evans, E.A., Crane, J., Hodges, A. and Osborne, J.L.: 2010. Potential economic impact of laurel wilt disease on the Florida avocado industry. HortTechnology 20, 234-238.

Fraedrich, S.W., Harrington, T.C., Rabaglia, R.J., Ulyshen, M.D., Mayfield Iii, A.E., Hanula, J.L., Eickwort, J.M. and Miller, D.R.: 2008. A fungal symbiont of the redbay ambrosia beetle causes a lethal wilt in redbay and other Lauraceae in the Southeastern United States. Plant Disease 92, 215-224.

Freeman, S., Sharon, M., Maymon, M., Mendel, Z., Protasov, A., Aoki, T., Eskalen, A. and O'Donnell, K.: 2013. Fusarium euwallaceae sp. nov.--a symbiotic fungus of Euwallacea sp., an invasive ambrosia beetle in Israel and California. Mycologia 105, 1595-1606.

Halfeld-Vieira, B.A., da Silva, W.L.M., Schurt, D.A., Ishida, A.K.N., de Souza, G.R. and Nechet, K.L.: 2015. Understanding the mechanism of biological control of passionfruit bacterial blight promoted by autochthonous phylloplane bacteria. Biological Control 80, 40-49.

Harrington, T.C., Fraedrich, S.W. and Achayeva, D.N.: 2008. Raffaelea lauricola, a new ambrosia beetle symbiont and pathogen on the Lauraceae. Mycotaxon 104, 399-404.

Huang, E. and Yousef, A.E.: 2014. Paenibacterin, a novel broad-spectrum lipopeptide antibiotic, neutralises endotoxins and promotes survival in a murine model of Pseudomonas aeruginosainduced sepsis. International Journal of Antimicrobial Agents 44, 74-77.

Iiyama, K., Otao, M., Mori, K., Mon, H., Lee, J.M., Kusakabe, T., Tashiro, K., Asano, S.I. and Yasunaga-Aoki, C.: 2014. Phylogenetic relationship of Paenibacillus species based on putative replication origin regions and analysis of an yheCD-like sequence found in this region. Bioscience, Biotechnology and Biochemistry 78, 891-897.

Jung, T.K., Kim, J.H. and Song, H.G.: 2012. Antifungal activity and plant growth promotion by rhizobacteria inhibiting growth of plant pathogenic fungi. Korean Journal of Microbiology 48, 16-21.

Kasson, M.T., O'Donnell, K., Rooney, A.P., Sink, S., Ploetz, R.C., Ploetz, J.N., Konkol, J.L., Carrillo, D., Freeman, S., Mendel, Z., Smith, J.A., Black, A.W., Hulcr, J., Bateman, C., Stefkova, K., Campbell, P.R., Geering, A.D.W., Dann, E.K., Eskalen, A., Mohotti, K., Short, D.P.G., Aoki, T., Fenstermacher, K.A., Davis, D.D. and Geiser, D.M.: 2013. An inordinate fondness for Fusarium: Phylogenetic diversity of fusaria cultivated by ambrosia beetles in the genus Euwallacea on avocado and other plant hosts. Fungal Genetics and Biology 56, 147-157.

Kim, O.S., Cho, Y.J., Lee, K., Yoon, S.H., Kim, M., Na, H., Park, S.C., Jeon, Y.S., Lee, J.H., Yi, H., Won, S. and Chun, J.: 2012. Introducing EzTaxon-e: A prokaryotic 16s rRNA gene sequence database with phylotypes that represent uncultured species. International Journal of Systematic and Evolutionary Microbiology 62, 716-721.

Koetschan, C., Hackl, T., Müller, T., Wolf, M., Förster, F. and Schultz, J.: 2012. ITS2 Database IV: Interactive taxon sampling for internal transcribed spacer 2 based phylogenies. Molecular Phylogenetics and Evolution 63, 585-588. 
Lee, Y.S., Nguyen, X.H., Cho, J.Y., Moon, J.H. and Kim, K.Y.: 2015. Isolation and antifungal activity of methyl 2,3-dihydroxybenzoate from Paenibacillus elgii HOA73. Microbial Pathogenesis.

Li, J., Liu, W., Luo, L., Dong, D., Liu, T., Zhang, T., Lu, C., Liu, D., Zhang, D. and Wu, H.: 2015. Expression of Paenibacillus polymyxa $\beta-1,3-1,4-$ glucanase in Streptomyces lydicus A01 improves its biocontrol effect against Botrytis cinerea. Biological Control 90, 141-147.

Lorentz, R.H., Ártico, S., Da Silveira, A.B., Einsfeld, A. and Corção, G.: 2006. Evaluation of antimicrobial activity in Paenibacillus spp. strains isolated from natural environment. Letters in Applied Microbiology 43, 541-547.

Lyngwi, N.A. and Joshi, S.R.: 2014 Chapter 3: Economically important Bacillus and related genera: a mini review. In: Sen, A. (Ed.), Biology of useful plants and microbes. Narosa Publishing House, New Delhi.

Mayfield Iii, A.E., Smith, J.A., Hughes, M. and Dreaden, T.J.: 2008. First report of Laurel wilt disease caused by a Raffaelea sp. on avocado in Florida. Plant Disease 92, 976.

McSpadden Gardener, B.B.: 2004. Ecology of Bacillus and Paenibacillus spp. in agricultural systems. Phytopathology 94, 1252-1258.

Nakamura, L.K.: 1990. Bacillus thiaminolyticus sp. nov., nom. rev. International Journal of Systematic Bacteriology 40, 242-246.

Nakamura, L.K.: 1996. Paenibacillus apiarius sp. nov. International Journal of Systematic Bacteriology 46, 688-693.

O'Donnell, K., Sink, S., Libeskind-Hadas, R., Hulcr, J., Kasson, M.T., Ploetz, R.C., Konkol, J.L., Ploetz, J.N., Carrillo, D., Campbell, A., Duncan, R.E., Liyanage, P.N.H., Eskalen, A., Na, F., Geiser, D.M., Bateman, C., Freeman, S., Mendel, Z., Sharon, M., Aoki, T., Cossé, A.A. and Rooney, A.P.: 2015. Discordant phylogenies suggest repeated host shifts in the FusariumEuwallacea ambrosia beetle mutualism. Fungal Genetics and Biology 82, 277-290.

Ploetz, R.C., Pérez-Martínez, J.M., Evans, E.A. and Inch, S.A.: 2011. Toward fungicidal management of laurel wilt of avocado. Plant Disease 95, 977-982.

Rooney, A.P., Price, N.P.J., Ray, K.J. and Kuo, T.M.: 2009. Isolation and characterization of rhamnolipid-producing bacterial strains from a biodiesel facility. FEMS Microbiology Letters $295,82-87$.

Saitou, N. and Nei, M.: 1987. The neighbor-joining method: a new method for reconstructing phylogenetic trees. Molecular biology and evolution 4, 406-425.

Tamura, K., Stecher, G., Peterson, D., Filipski, A. and Kumar, S.: 2013. MEGA6: Molecular evolutionary genetics analysis version 6.0. Molecular Biology and Evolution 30, 2725-2729. 
Umeda, C., Eskalen, A. and Paine, T.D.: 2016 Polyphagous shot hole borer and fusarium dieback in California, Insects and Diseases of Mediterranean Forest Systemspp. 757-767.

Vater, J., Niu, B., Dietel, K. and Borriss, R.: 2015. Characterization of Novel Fusaricidins Produced by Paenibacillus polymyxa-M1 Using MALDI-TOF Mass Spectrometry. Journal of the American Society for Mass Spectrometry 26, 1548-1558.

Von Der Weid, I., Alviano, D.S., Santos, A.L.S., Soares, R.M.A., Alviano, C.S. and Seldin, L.: 2003. Antimicrobial activity of Paenibacillus peoriae strain NRRL BD-62 against a broad spectrum of phytopathogenic bacteria and fungi. Journal of Applied Microbiology 95, 11431151.

Ward, T.J., Bielawski, J.P., Corby Kistler, H., Sullivan, E. and O'Donnell, K.: 2002. Ancestral polymorphism and adaptive evolution in the trichothecene mycotoxin gene cluster of phytopathogenic Fusarium. Proceedings of the National Academy of Sciences of the United States of America 99, 9278-9283.

Xu, S. and Kim, B.S.: 2016. Evaluation of Paenibacillus polymyxa strain SC09-21 for biocontrol of Phytophthora blight and growth stimulation in pepper plants. Tropical Plant Pathology 41, 162-168.

Zhang, Y.J., Zhang, S., Liu, X.Z., Wen, H.A. and Wang, M.: 2010. A simple method of genomic DNA extraction suitable for analysis of bulk fungal strains. Letters in Applied Microbiology 51, 114-118. 

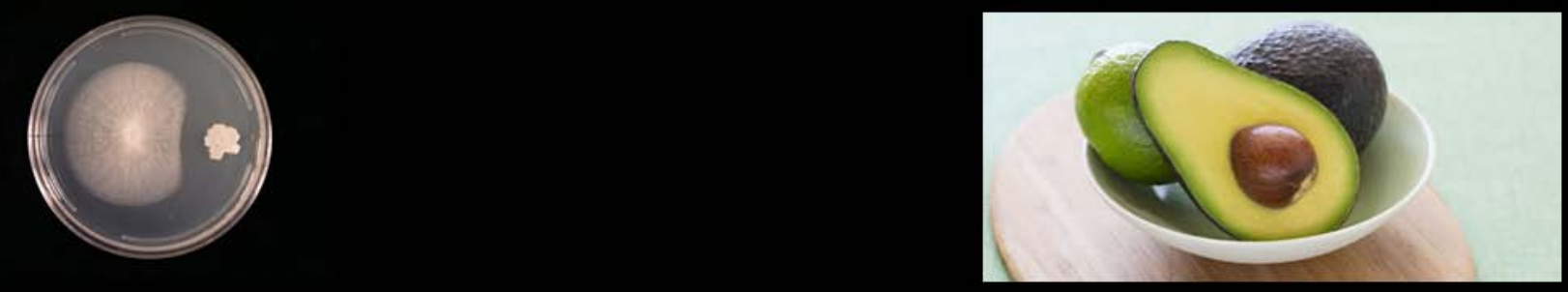